\title{
Eugène Ébodé, Grand Père Boni et les contes de la savane
}

Simona Rossi

\section{(2) OpenEdition}

1 Journals

\section{Edizione digitale}

URL: http://journals.openedition.org/studifrancesi/28188

DOI: 10.4000/studifrancesi.28188

ISSN: 2421-5856

\section{Editore}

Rosenberg \& Sellier

\section{Edizione cartacea}

Data di pubblicazione: 31 décembre 2006

Paginazione: 647-648

ISSN: 0039-2944

\section{Notizia bibliografica digitale}

Simona Rossi, «Eugène Ébodé, Grand Père Boni et les contes de la savane », Studi Francesi [Online], 150 (L | III) | 2006, online dal 30 novembre 2015, consultato il 08 novembre 2020. URL : http:// journals.openedition.org/studifrancesi/28188; DOI : https://doi.org/10.4000/studifrancesi.28188

Questo documento è stato generato automaticamente il 8 novembre 2020.

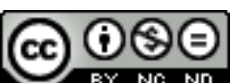

Studi Francesi è distribuita con Licenza Creative Commons Attribuzione - Non commerciale - Non opere derivate 4.0 Internazionale. 


\title{
Eugène Ébodé, Grand Père Boni et les contes de la savane
}

\author{
Simona Rossi
}

\section{NOTIZIA}

EUGÈNE ÉBODÉ, Grand Père Boni et les contes de la savane, Archères, Éditions Monde Global, 2006, pp. 109.

1 In questa raccolta di dieci novelle, Eugène Ébodé racconta l'Africa. Con l'umorismo e la freschezza che lo contraddistinguono da sempre, egli trasporta i suoi lettori in un mondo dalle mille sfaccettature, innocente e crudele al tempo stesso, un mondo completamente agli antipodi di quello europeo, i cui riti e misteri affascinano e spaventano. Sono racconti che non hanno età, quelli di Ébodé, adatti sia per gli adulti che per i bambini, poiché hanno un unico fine: suscitare emozioni. Man mano che le pagine scorrono, quasi inconsciamente, il lettore desidera essere lì, in Africa, sentire il sole sulla pelle, godere del calore degli abitanti dei villaggi africani, partecipare alle feste descritte, così piene di vita, di musica e di colori. Il lettore desidera soprattutto poter ascoltare all'infinito il narratore Père Boni, la cui vita avventurosa lo ha reso un formidabile conteur. Alla luce della luna, sotto il grande baobab, questo vecchio di almeno cent'anni, ma incredibilmente vitale, ha allietato le notti infantili dell'autore, che decide ora di regalare al mondo la magia delle sue storie, facendone il fulcro delle sue novelle. Anche il lettore si siede in cerchio sotto il baobab, allora, e ascolta: è così che si ritrova coinvolto nella rivolta degli asini, i quali, capitanati da un asino "diverso", privo di croce tatuata sulla schiena, mirano ad ottenere il rispetto degli uomini, poiché non esistono esseri superiori e inferiori; è così che assiste alla perdita dei poteri del vecchio pluviateur Samoka - uomo che chiama la pioggia - a causa della disubbidienza degli uomini, che ha provocato la collera degli dei; che osserva le capre punire un ragazzino, reo di tirare sempre le loro barbichettes, creandone delle finte, piene di spine; che sorride di fronte all'intelligenza di un gatto che stana un temibile 
leopardo prima di un famoso cacciatore e per questo viene ricompensato con i ratti più prelibati del paese, etc.

2 A metà strada tra la fantasia e la realtà, tanto che ad un certo punto l'autore ritiene opportuno avvisare i lettori che nelle vicende sono presenti anche elementi di fantasia, questi racconti di Ébodé costituiscono una lettura piacevole che permette di entrare in contatto con un aspetto affascinante del mondo africano, le cui regole di vita sono del tutto diverse da quelle vigenti nella nostra realtà occidentale, ma non per questo meno ricche di risvolti interessanti. L'ultima novella della raccolta, tra l'altro, vede una giovane donna africana emigrata in un altro paese coi genitori adottivi, decidere di tornare nel luogo in cui è nata e diventare conteuse. L'opera di Père Boni, dunque proseguirà anche dopo la sua morte: l'Africa continuerà a raccontarsi e noi continueremo ad ascoltala, sperando che questo ascolto generi presto un dialogo altrettanto profondo. 